\title{
Health System Strengthening Using Problem Solving for Better Health in Lesotho
}

Grace Hyojung Yoon ( $\nabla$ ghyoon@bu.edu )

Boston University School of Public Health https://orcid.org/0000-0002-3849-1947

\section{Shannon N Ogden}

Boston University School of Public Health

\section{Elizabeth Limakatso Nkabane-Nkholongo}

Lesotho-Boston Health Alliance

\section{Mantoetse Jobo}

Lesotho-Boston Health Alliance

Chelsea M McGuire

Boston University School of Medicine

\section{Sebaka Malope}

Lesotho-Boston Health Alliance

\section{Pamela Hoyt-Hudson}

Dreyfus Health Research Center

\section{Barry H Smith}

Dreyfus Health Research Center

\section{Brian W Jack}

Boston University School of Medicine

\section{Research Article}

Keywords: international health, health system strengthening, workforce capacity, Lesotho, sub-Saharan Africa

Posted Date: June 9th, 2021

DOl: https://doi.org/10.21203/rs.3.rs-604692/v1

License: (a) (i) This work is licensed under a Creative Commons Attribution 4.0 International License. Read Full License 


\section{Abstract}

Background Problem Solving for Better Health ${ }^{\circledR}\left(\mathrm{PSBH} \circledast{ }^{\circledR}\right)$ is a system-strengthening workshop designed to empower healthcare workers ( $\mathrm{HCWs)} \mathrm{to} \mathrm{solve} \mathrm{problems.} \mathrm{We} \mathrm{report} \mathrm{on} \mathrm{the} \mathrm{perspectives} \mathrm{of}$ HCWs trained in PSBH to better understand the impact and challenges of PSBH in Lesotho, a country with among the highest prevalence of HIV and tuberculosis in the world.

Methods HCWs who attended PSBH workshops in 2018 - 2019 were interviewed using a semi-structured interview guide developed from a hybrid conceptual framework that captured the HCWs' personal, interpersonal, and systemic levels of experience. Interviews were transcribed and analyzed using the framework matrix analysis method using NVivo.

Results We interviewed 22 of the 86 HCWs who participated in PSBH workshops in 2018-2019. Twenty out of 22 interview participants reported that they initiated a project that was planned during the PSBH workshop. Participants reported that PSBH provided them with a new way of viewing, addressing, and solving everyday problems that can have a tangible impact on the function of healthcare facilities and the health of the community. Trainees were motivated to see the impact of their work in their jobs and in the work of subordinates as a sustained ripple effect favoring quality improvement. Participants suggested that training of district administrative leaders in PSBH would facilitate successful dissemination and help overcome the challenge of adding more work for the already-overburdened HCWs.

Conclusions HCWs in Lesotho report that PSBH assists them in solving problems in their everyday work. This led the national Ministry of Health Quality Assurance Unit to request that PSBH workshops be conducted to train Ministry personnel to allow them to oversee national dissemination of PSBH, thereby fulfilling a component of the National Quality Assurance Strategic Objectives.

\section{Introduction}

Health-system strengthening programs are of crucial importance, especially in low-resource nations such as Lesotho. The Lesotho healthcare system serves a population of approximately 2.14 million people, where the average per capita health expenditure is $\$ 276$ per year and average life expectancy is 53 years (1). Predominantly rural and mountainous, Lesotho faces many health challenges, such as having among the highest HIV/AIDS and tuberculosis prevalence in the world $(2,3)$. Identifying low-cost methods to strengthen all aspects of the health system is a priority.

\section{Lesotho-Boston Health Alliance}

Lesotho-Boston Health Alliance (LeBoHA) is a registered, non-profit organization in Lesotho that aims to strengthen healthcare management, policy, planning, and human resource capacity. LeBoHA has partnered with the Lesotho Ministry of Health $(\mathrm{MOH})$ to train health care workers (HCWs) in a quality improvement and problem-solving methodology called Problem Solving for Better Health ${ }^{\circledR}\left(\mathrm{PSBH}^{\circledR}\right)$. 
PSBH was developed to harness "human potential and possibilities for change (4)." Through LeBoHA, Boston University faculty and Dreyfus Health Foundation staff partnered with the Lesotho $\mathrm{MOH}$ to train HCWs in the PSBH methodology with a focus on the HIV/AIDS epidemic since the early 2000s.

Participants in these early workshops were mentored by international facilitators and several have now become experienced workshop leaders. Currently, all PSBH workshop facilitators are Basotho (the people of Lesotho), and workshops are largely delivered in Sesotho (the language of Lesotho).

LeBoHA also collaborated with the MOH to establish the nation's first accredited postgraduate physician specialty training program, called the Family Medicine Specialty Training Program (FMSTP)(5). FMSTP trainees work in most of the country's 10 districts as clinician-administrators. Since 2018, LeBoHA has trained 11 FMSTP trainees in PSBH, most of which have gone on to co-facilitate a PSBH workshops in their districts.

\section{Program Description}

PSBH is based on the scientific method and targets HCWs at all levels. Its major focus is to promote broad, sustainable skill-building by encouraging participants to identify a problem that is within their scope of everyday work and within their authority to address. The workshop facilitates the attendees' development of a practical plan to address the identified problem using little to no funds, at least at the start (6). In each 2.5-day PSBH workshop, HCWs are taught how to:

1. Define the problem (size, cause, and contributing factors)

2. Prioritize the problem (focus on one realistic piece of the problem)

3. Define a solution, asking a "good question" (doing what, with whom, where)

4. Create an action plan (why, what, how, means of evaluation)

5. Take action (project conducted over 6-12 months)

6. Follow-up (workshop facilitators monitor and provide advice over time)

By the conclusion of each workshop, participants have written a plan detailing how to conduct their project and made a commitment to carry out their projects over a period of six months or more. They receive a one-day follow-up refresher training and report results according to pre-determined and objective evaluation criteria after three to six months of the initial training. PSBH facilitators monitor the progress of participant's projects, providing advice and collating results and impact.

PSBH has a successful track record around the world. The workshop has been taught worldwide for over 30 years, including 32 countries across Africa, Asia, Eastern Europe, the Middle East, and North America. To date, more than 70,000 healthcare professionals have participated in PSBH workshops and have completed some 50,000 quality-improvement projects. For Lesotho, PSBH is a low-cost means of catalyzing projects that address problems important to HCWs and the people they serve across the country (4).

Despite the expansion of PSBH in Lesotho, there has not been a systematic evaluation of the program involving perspectives of participants. To contribute to the program's continuous adaptation to best fit the 
needs of Basotho HCWs and draw on generalizable lessons for dissemination of PSBH in similar settings, we aim to explore the perspectives of participants in recent PSBH workshops conducted in 201819. The purpose of this qualitative evaluation is to identify the impact of PSBH on participants' a) perceived capacity to solve problems in their daily health-sector work and b) beliefs about the potential of $\mathrm{PSBH}$ to be used as a tool to advance Lesotho's healthcare improvement strategy.

\section{Methods}

We carried out a qualitative study of PSBH workshop participants across seven of the ten districts of Lesotho.

\section{Conceptual framework}

The semi-structured interview guide was designed to capture major components of the PSBH program in our evaluation, with themes spanning individual growth to systemic impact. Our PSBH evaluation framework (Fig. 1) was adapted as a hybrid from three previously published frameworks used in the fields of management and public health:

1. Six-step problem-solving model (7): Major areas of systemic impact that arises from implementation of a problem-solving technique (Outer cycle)

2. Empowerment framework (8): Individual growth represented by positional acknowledgement and situational awareness (Top of the inner ladder)

3. Problem-based/action-based integrative learning model (9): Intrinsic motivation leading to continued participation beyond the workshop; specific components for personal and interpersonal participation which both lead to skills-building to breakdown complex problems into small, feasible steps (Rest of the inner ladder)

\section{Development of the interview guide}

A semi-structured interview guide was developed based on the conceptual framework with feedback from experienced PSBH facilitators and LeBoHA leadership. The interview guide was created to explore the three major categories described in the conceptual model and was used for all interviews.

\section{Data collection}

Between June-September 2019, GHY conducted interviews with 2018-2019 PSBH workshop participants. Interview participants were recruited via convenience sampling from a list of participants provided by LeBoHA. The interviews were conducted individually in-person or by phone. GHY transcribed 16 audiorecorded interviews semi-verbatim and removed all identifying data. Semi-verbatim transcription, in the context of this study, means that extraneous sounds and remarks were omitted in the transcription, and words were added, as appropriate, for clarity. The other six participants' responses were recorded by manual notetaking. Field notes from these interviews were elaborated and contextualized by the 
interviewer, and typed into a separate, deidentified document. All deidentified documents were uploaded onto the coding software, NVivo (QSR International Pty Ltd., version 11, 2017), for analysis.

\section{Analysis}

A preliminary codebook was developed to identify major informational categories, based on the domains outlined in the analytic framework. Additional overarching codes that were not part of the analytic framework, were incorporated to allow for inductive grouping of additional relevant data. These consisted of the codes describing barriers, facilitators, golden quotes for especially notable quotes, and a miscellaneous category for data not fitting into any of the codes developed above (Appendix 1).

Using the framework matrix analysis method(10), two authors (GHY and SNO) coded all transcripts. Initially, four transcripts were double coded to reach consensus on the operationalization of the codes. Several sub-codes were identified inductively and added to the codebook throughout the double-coding process. Once both coders were comfortable with the coding mechanism (inter-rater reliability $=90.2 \%$ ), the remainder of the transcripts were divided and single-coded. Coders held weekly meetings to discuss and reconcile any coding concerns. Results were discussed and validated with an experienced PSBH facilitator (SM) and the LeBoHA director (ELN). Participant locations and roles were obtained from the LeBoHA PSBH database. Titles of projects designed during the PSBH workshops were obtained from the LeBoHA PSBH database or elicited during interviews.

\section{Ethical considerations}

After informing the participants of the study purpose and associated risks (i.e., potential breach of confidentiality despite de-identification of interview transcriptions), the interviewer received verbal informed consent prior to the interview and beginning of note taking or audio recording. Because of the low-risk nature of the study, written consent was not required. For one participant who declined audio recording and for five interviews that could not be recorded due to lack of recording capability or background noise, the interviewer took notes on a secure laptop.

\section{Results}

Out of the 86 participants trained in 2018-2019, 37 were reached and 22 consented and completed the interviews. Many of the interviewees were nurses in varying capacities, including public health nurses, nurse matrons, and nurses-in-charge. We combined the roles medical officers and medical superintendents under the category of physicians. District health managers are also licensed physicians, but they were categorized separately because their leadership roles spanned both clinical and management responsibilities within their districts (Table 1). Seven of the 10 districts in Lesotho were represented. Twenty of the 22 interviewees $(90.9 \%)$ had initiated a project designed at the PSBH workshop they attended (Table 2). Generally, projects included efforts to improve clinical documentation, reduce patient wait-times, and improve the supply of medications, among others. 
Table 1

Description of Interviewees ( $\mathrm{n}=22)$

\begin{tabular}{|ll|}
\hline Role & $\boldsymbol{n}(\%)$ \\
\hline District health manager & $5(22.7 \%)$ \\
\hline Physicians & $3(13.6 \%)$ \\
\hline Pharmacy staff & $3(13.6 \%)$ \\
\hline Laboratory staff & $3(13.6 \%)$ \\
\hline Nurses & $7(31.8 \%)$ \\
\hline PSBH Facilitator & $1(4.5 \%)$ \\
\hline District in Lesotho & \\
\hline Leribe & $9(40.9 \%)$ \\
\hline Mafeteng & $4(18.2 \%)$ \\
\hline Mokhotlong & $1(4.5 \%)$ \\
\hline Berea & $4(18.2 \%)$ \\
\hline Butha Buthe & $1(4.5 \%)$ \\
\hline Thaba Tseka & $3(13.6 \%)$ \\
\hline
\end{tabular}


Table 2

PSBH Projects Designed by Interview Respondents

\section{Helping the hospital attain and maintain hygienic toilets}

2. Conducting supportive supervision in local health centers

3. Improving documentation and upgraded implementation of laboratory quality management systems and increasing performance

4. Raising the quality of nursing documentation

5. To decrease percentage of patients who are waiting for care at the end of day at the general outpatient department

6. Reducing the number of emergency cesarean sections referred to [hospital name] on weekends and public holidays

7. Addressing documentation gaps which lead to poor nursing care

8. Improving service delivery in the pharmacy

9. Increasing competency in resuscitation among casualty staff

10. Reducing the percentage of nurses who do not adhere to the use of "Integrated Management of Childhood IIIness" guidelines

11. a) Improving the productivity of District Health Management Team monthly meetings

b) Expanding primary care for local miners

12. Improving upper management's performance with quality assurance scores

13. Ensuring adequate drug supply in the casualty department

14. Decreasing patient wait-times in the outpatient department

15. Address long-term stock-out of Pentrol 400 (a lab reagent)

16. Obtaining new and repairing broken lab instruments

17. Increasing percentage of "Category A Commodities" (pharmaceuticals) that are stocked according to standards

18. Reducing the percentage of non-compliant prescribing nurses when treating common illnesses

19. Increasing screening for renal complications

20. Improving management and quality of care for malnourished children

The analysis resulted in the identification of four themes. Each key theme is discussed below with quotes from the participants included to exemplify each finding.

Participant perspectives on the impact of PSBH training 
Most participants described PSBH as an effective skills-building workshop that shifted the way in which they viewed everyday workplace problems. One participant illustrated this by describing what they took away from the workshop:

"Why is it a problem, what that problem is, and why is that problem your problem? So those are the best things that I took from the training, because if I know all those answers then it helps me to go to the root, the cause, of the problem. It also helps me to shape my outcome, the expected outcome and things that are going to lead me to that expected outcome. Even if those things, [if] I've got them, if they are feasible and if they are doable. If not doable, then I know then I should be looking for things that are doable." (District Health Manager 1)

When asked about weighing the benefits and time needed to attend a PSBH workshop, participants generally agreed that its impact outweighed the costs and described the real-world, patient-level impact that PSBH projects have had on their healthcare facilities:

"You can see the improvement that has happened, that it wasn't just for the sake of having the workshop. Now [because of the impact of my project] the patients are returning happy, being seen by the doctor. [...] They were taking their whole day to come to see the doctor. But now if they can take a few hours, they will still go to do other things afterwards, or they will still go to back to work afterwards." (Physician 1)

Another participant noted that designing a quality-improvement project using PSBH methodology was beneficial because it provides a data-oriented approach in daily work and has the potential to impact the health of the community while saving costs.

"I think it will be beneficial, yes, because we are encouraging nurses to use their data. If you use your data, you will see the hiccups. So, where we see that we are having the problems with the immunization, they can see how many projects we can do in order to improve that indicator for child survival [...] it's going to benefit the whole country. Economically we are going to be able to save the country so much money, without them [the $\mathrm{MOH}$ ] coming down to us to try and solve things for us. So, it's at the local level [that] we try to provide many solutions for ourselves, and not depend on the whole country." (District Health Manager 2)

\section{Engagement and continued use of PSBH skills}

Many trainees learned from carrying out their PSBH projects and practicing PSBH tenets in everyday work. Below are examples contextualizing this statement using data organized in three subtopics according to the conceptual framework: (1) intrinsic motivation, (2) personal participation, and (3) interpersonal participation.

Intrinsic motivation: Participants shared examples of how PSBH helped them to improve the work they do each day, which then motivates to them to continue practicing the problem-solving methods learned from PSBH. 
"So, identifying the problem and trying to deal with it, in reality, is not really easy. But the good thing is, should you be able to follow through and be able to follow up to the end, then I'm telling you we are going to celebrate every day. [...] I think it [PSBH] can help a lot in helping our service delivery." (Nurse 1)

Interpersonal participation: Participants stressed the importance of having buy-in from local leaders in their healthcare facility and national health leaders in the $\mathrm{MOH}$ for the workshop to have true impact and reach:

"We have to convince the leaders. We need to identify the leaders, people who can actually push it, then we won't have many barriers. It just needs sustainability and ownership (Nurse 1)

Many of the attendees in leadership positions, such as this District Health Manager, commented on how encouraging it was to see the impact of PSBH not only in their work, but also in the work of their coworkers. This participant expressed gaining motivation to continue practicing PSBH from seeing the impact PSBH has on other HCWs:

"For me, I have a great desire [to continue] because I've seen a great impact of [PSBH]. Because even the way that even from our cleaner, from our head of units, from the nurses, from us, everybody, I've actually taught them [...] a tactic of saying, "What is the gap? [...] What is the cause of this?" So then we turn these 'causes' into to activities. Therefore, with that, we've seen that our planning is very effective, so my desire is to continue doing it because it actually is an effective way of planning." (District Health Manager 3 )

Personal participation: The applicability of the lessons learned from PSBH in their own personal work and everyday activities that mattered to them in their jobs was mentioned by several interviewees. A participant noted that while she had learned problem-solving concepts at the workshop, gaining a fuller understanding of the PSBH method came by practicing the skills through project implementation.

\section{Institutional Impact of PSBH}

We found numerous examples of successful participant projects having tangible impact on the function of the hospital or healthcare facility in which they work. For example, this lab manager recounts their success at improving the District laboratory by employing steps learned at their PSBH workshop:

"Yes, it was about implementing QMS (quality management systems) [...] The quality starts from where the samples have been taken from the patients up until the results are given back to the patients. We have to monitor all those steps so that other people will see that we have quality results [...] We have a tool that we have to use to assess the statistics that was approved by the WHO. So PSBH helps us to achieve our goals to accreditation. Yes, that's the tool that we used. We really saw the improvement from [using] the tool." (Lab staff 1)

Another participant recalls an issue they faced with the hospital's finance department in getting necessary blood pressure machines for the inpatient wards. They explain how the PSBH workshop helped them organize and communicate their problem logically, allowing them to resolve the issue at the local level: 
“Before, I would just request, 'Can I have 1, 2, 3..' then they'll just say 'no, we don't have.' You know how finance offices work. When they say they don't have money, they don't have money. But after I explained, 'we are having problems which leads to mismanagement of patients,' it starts to make some sense now to the Finance Officer [...] I had to justify the end strategy. I got the blood pressure machines that I wanted." (Nurse 3)

\section{Facilitators and Barriers to Dissemination of PSBH}

A major facilitator was proactive leadership, such as this participant who implemented informal downstream training of PSBH principles to local clinic nurses:

"They [PSBH lessons] help me a lot because when we are doing our supportive supervision and mentorship, we encourage nurses, if we have problems in their facilities, they can make a three-month to six-month quality improvement project on their own to help improve their indicators in the health centers." (District Health Manager 4)

Participants who are leaders in their departments stated that their own practice of the PSBH methodology created a ripple effect of new quality improvement projects in their facility. This occurred via an informal process of step-down training and knowledge-sharing from the PSBH workshop participants to other HCWs in the same workplace.

"I did step-down training in the clinic. Now even the cleaners must do a project to improve quality of their work. At the time of their training, they were very motivated [...] My junior staff, they no longer ask me to solve problems for them. They now are committed to solving the problems on their own. They suggest steps to solve their own problems." (Nurse 2)

Another critical facilitator was the generalizability of the workshop, seen by participants who felt that every healthcare worker could benefit from learning the practical lessons that PSBH teaches:

"I think everyone could benefit, everyone. It wasn't specific for medical officers. It was general, everyone would benefit." (Nurse 4)

When asked about any foreseeable barriers to the further dissemination of the PSBH workshops across their District and Lesotho, participants mentioned the stresses experienced by the limited number of skilled HCWs. Specially, the same, small number of healthcare professionals often receive specialized workshops and trainings from both the $\mathrm{MOH}$ and other NGOs, to the point where they find less time to do their primary clinical and leadership duties. Also mentioned were the lack of resources (money, time, and staff) that make it difficult for existing $\mathrm{HCWs}$ to also take on the responsibility of training others to further disseminate the PSBH method:

"The challenge is that we are short-staffed [...] I think with these new nurses, I will do it. Because now I will know that I have certain number of nurses in the male ward, and permanently, certain number of nurses in female ward, and other wards. So, when they get the training, on [how to provide better] patient care, I think it would be perfect." (Nurse 5)

Page 10/15 


\section{Discussion}

The evaluation of PSBH workshops in this study provides evidence that the PSBH process in Lesotho positively influenced the ability of health workers to solve problems that are within the scope of their jobs. $\mathrm{PSBH}$ has also influenced national leaders in the $\mathrm{MoH}$ to incorporate this methodology into the national quality-assurance strategy, and into the in-service training of all nurses and postgraduate physicians providing both national dissemination and sustainability.

\section{PSBH Represents an Alternative Approach to Problem Solving}

In Lesotho, as in other low-resource settings, there is often an over-reliance on centralized solutions to everyday problems (11). The results of our evaluation of PSBH in Lesotho suggest that it is a viable strategy for Lesotho to provide an alternative to programs that offer "top-down" approaches to problemsolving. Numerous global health organizations have worked with local partners to build capacitystrengthening programs in health that use a variety of methodologies, such as continuous quality improvement. Reliance on centralized resources for local health system issues can lead to limited transparency, priority setting and use of evidence relevant to regional contexts (12).

PSBH differs from a centralized approach in several important ways. It emphasizes a decentralized and egalitarian (equity-fostering) approach, where problem-solving is the responsibility of health workers at all levels. PSBH is a highly adaptable short curriculum and process of direct application that teaches individuals at all levels of the health system the skills needed to identify and solve problems they face and over which they have authority. Training in PSBH for District Medical Officers, health-center nurses, pharmacists, laboratory technicians and food and environmental services staff, among others, is a strong strategy to establish a quality-improvement culture in resource-limited settings. This frontline response promotes a cultural shift that changes the way problems are considered and addressed, releasing the innate potential of workers to solve problems in their facilities. Participants feel encouraged to take further action when they see the impact of their own PSBH projects on the quality-improvement work of their subordinates, observing that they are intentionally (or unintentionally) spreading the PSBH methodology in their health facilities.

\section{Post-Workshop Completion of PSBH Projects}

Mastering problem-solving skills requires not only creating a plan for quality-improvement projects during the PSBH workshop, but also implementing and evaluating those solutions once back on the job. Consistent post-workshop coaching and mentoring to assist participants in seeing their projects to completion is an important component of PSBH. Training MoH Quality Assurance Unit (QAU), District Health Management Teams, and District Medical Officers in PSBH will help make this a practical reality.

In our evaluation, participants reported that successful completion of their projects was hindered by lacking peers and managers who knew and understood the PSBH methodology. They suggested that the rate of successful project completion could be improved by training $\mathrm{MoH}$ and District health leaders in $\mathrm{PSBH}$, enabling them to provide advice and support. Training government staff in PSBH would also 
increase their appreciation of the process, resulting in an opportunity for the health workers to discuss and refine their workshop-created problem-solving plans with them and help align the projects with MoH's strategic goals, while providing dedicated time and resources for project completion. Such support would give the participants' projects value and meaning, while providing an opportunity for $\mathrm{MoH}$ staff to become aware of problems and solutions at the grass-roots level.

\section{Limitations}

The limitations of this study were several. First, we were unable to represent three districts in our analysis: Qacha's Nek, Quthing and Mohales Hoek, limiting the ability to generalize our findings to Lesotho as a whole. Secondly, the data collection was dependent on a single interviewer's availability in each District and their success in contacting potential participants in scheduling of participant interviews over a short time of three months. In addition, there may have been courtesy bias in the participants' responses since the interviewer was a LeBoHA-affiliated, non-native interviewer not previously known to the interview participants. For qualitative analysis of the data, only one author actively collected data by interviewing the participants, so the second coder did not have the same insights that would have been helpful with respect to contextualizing the interviews that they coded. Finally, the interpretation of findings by the authors may be positively biased by their knowledge of the training and funding organizations associated with PSBH.

\section{Conclusion}

The partnership of LeBoHA, the Dreyfus Foundation and the MoH offers the promise of incorporating PSBH affordably and sustainably into Lesotho's national quality-assurance strategy. In addition, evaluating the impact of PSBH in a small country like Lesotho can serve as a guide for assessing the potential usefulness of implementing similar or different problem-solving methodologies in other countries or regions with parallel characteristics. Demonstrable, quantitative improvements in hospital function and patient outcomes because of national dissemination will provide the ultimate test of PSBH's value as a quality improvement tool.

\section{Declarations}

$>$

\section{Ethics approval and consent to participate}

All study procedures were approved by the Boston University Medical Campus Institutional Review Board (IRB; Protocol number H-38913). A separate Lesotho IRB was not obtained as this study fell under the memorandum of understanding between the Lesotho $\mathrm{MOH}$ and LeBoHA allowing quality improvement training programs.

\section{Consent for publication}


All authors consented to publication of this current document. All participants consented to their participation with the possibility that this information may be published in a deidentified manner.

\section{Competing interests}

Authors have no competing interests to disclose.

\section{Funding}

Problem Solving for Better Health ${ }^{\circledR}\left(\mathrm{PSBH}^{\circledR}\right)$ workshops are supported by the Dreyfus Health Foundation and the Dreyfus Health Policy and Research Center, New York, NY. Funding for GHY's travel to Lesotho June - September 2019 was provided by the Jessica Jennifer Cohen Foundation. Funding for her time in Lesotho was provided by Boston University's Institute for Health System Innovation and Policy. SNO was supported by a training grant from the National Institute on Drug Abuse (T32DA041898). CMM was supported by the T32HP10028 Academic Fellowship Program at Boston University, and by the National Center for Advancing Translational Sciences, National Institutes of Health through BU-CTSI Grant Number 1UL1TR001430.

\section{Acknowledgements}

We would like to acknowledge the following individuals for their contributions to this study: Mangaka Kanjane, Phethetso Lephallo, Taole Manope, and Moretlo Thulo-Jasong. We also thank all FMSTP trainees who taught PSBH in their districts. We are also grateful for feedback from Sarah Lipson throughout various steps of this study and early versions of this manuscript.

\section{References}

1. Lesotho. WHO [Internet]. 2020 [cited 2020 Jun 23]; Available from: http://www.who.int/countries/lso/en/.

2. Foreign direct investment. to Africa defies global slump, rises 11\% [Internet]. UNCTAD. 2019 [cited 2020 Jun 23]. Available from: https://unctad.org/en/pages/newsdetails.aspx? OriginalVersion ID=2109.

3. National Institute of Statistics, Directorate General for Health, ICF International. Lesotho Demographic and health survey 2014 [Internet]. Lesotho Ministry of Health. 2015. 1-457 p. Available from: http://www.gov.ls/health/.

4. Smith BH, Hoyt-Hudson P, Fitzpatrick J. Problem Solving for Better Health: A Global Perspective. New York: Springer New York LLC; 2010.

5. Malope S, Malope S, Nkabane-Nkholongo E, Schumacher R, Jack B, Babich LP, et al. Development of a family medicine specialty training program (FMSTP) in Lesotho. Ann Glob Heal [Internet]. 2015;81(1):39. Available from: http://dx.doi.org/10.1016/j.aogh.2015.02.600. 
6. Hoyt P. An international approach to Problem Solving for Better Health Nursing ${ }^{\text {TM }}$ (PSBHN): Original article. Int Nurs Rev [Internet]. 2007 Mar [cited 2020 Jun 23];54(1):100-6. Available from: https://pubmed.ncbi.nlm.nih.gov/17305964/.

7. Restructuring Associates I. Six-Step Problem Solving Model. 2008.

8. Kolb SM, Stuart SK. Active Problem Solving: A Model for Empowerment. Teach Except Child. 2005;38(2):14-20.

9. Scott KS. An Integrative Framework for Problem-Based Learning and Action Learning: Promoting Evidence-Based Design and Evaluation in Leadership Development. Hum Resour Dev Rev. 2017; Vol. 16:3-34 p.

10. Gale NK, Heath G, Cameron E, Rashid S, Redwood S. Using the framework method for the analysis of qualitative data in multi-disciplinary health research. BMC Med Res Methodol [Internet]. 2013 [cited 2020 Jun 23];13(1). Available from: https://pubmed.ncbi.nlm.nih.gov/24047204/.

11. Frumence G, Nyamhanga T, Mwangu M, Hurtig AK. The dependency on central government funding of decentralised health systems: Experiences of the challenges and coping strategies in the Kongwa District, Tanzania. BMC Health Serv Res [Internet]. 2014 Jan 25 [cited 2021 May 10];14. Available from: https://pubmed.ncbi.nlm.nih.gov/24460781/.

12. World Health Organization. Improving Health System Financing in Low Income Countries. [Internet]. [cited 2021 May 10]. Available from: https://www.who.int/management/background_5.pdf?ua=1.

\section{Figures}




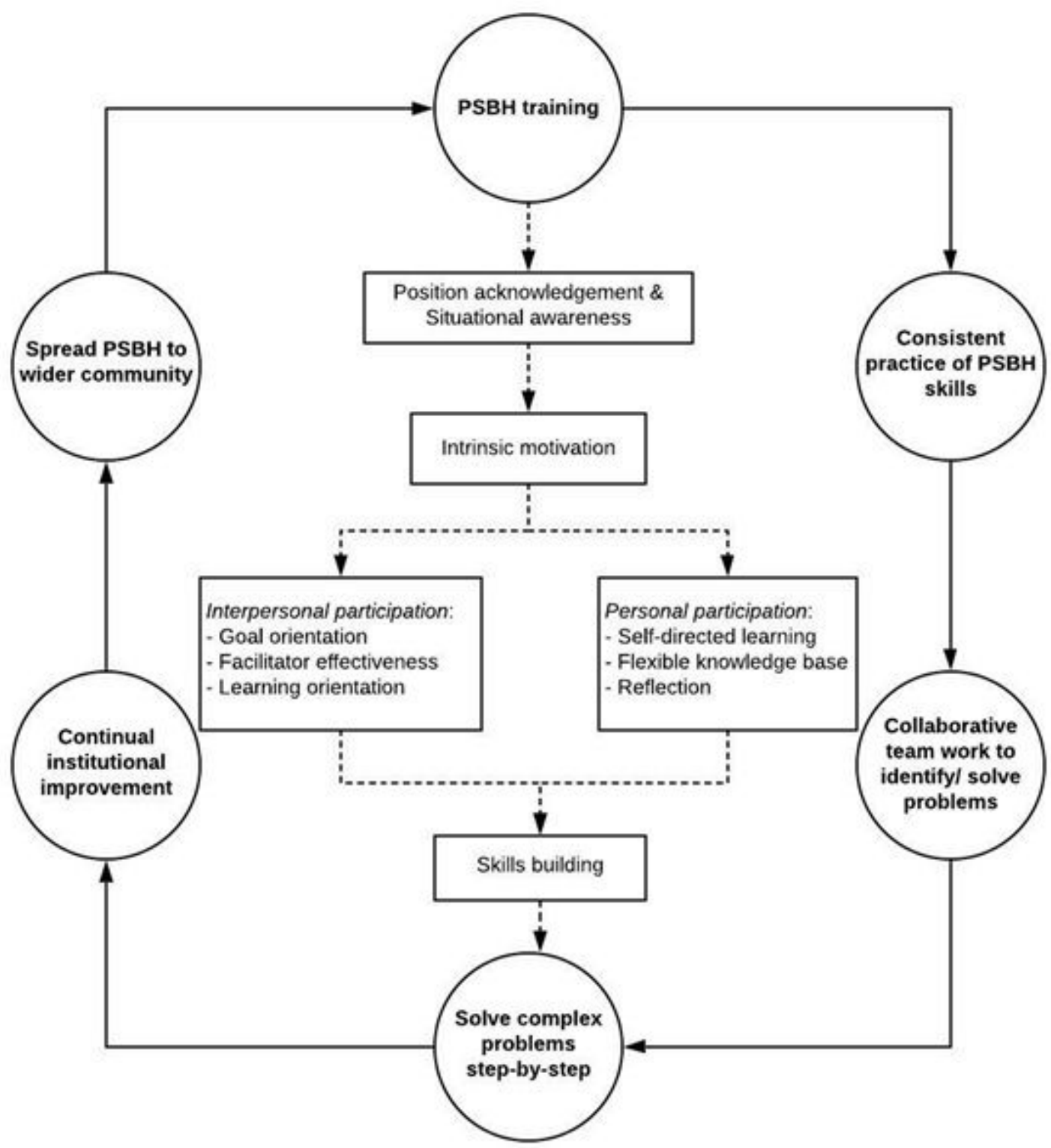

Figure 1

PSBH Evaluation Framework

\section{Supplementary Files}

This is a list of supplementary files associated with this preprint. Click to download.

- Appendixl.docx 